\title{
NUMERICAL ANALYSIS OF THE BEHAVIOR OF SPECIAL DOUBLE-ROW SUPPORT STRUCTURE
}

\author{
Kai Fang ${ }^{1}$, Zhongmiao Zhang ${ }^{2}$, Xingwang Liu ${ }^{3}$, Qianqing Zhang ${ }^{4}$, Cungang Lin $^{5}$ \\ ${ }_{1,2,5}$ Institute of Geotechnical Engineering, Zhejiang University, Hangzhou 310058, China \\ ${ }^{3}$ Zhejiang Province Institute of Architectural Design and Research, Hangzhou 310006, China \\ ${ }^{4}$ Geotechnical and Structural Engineering Research Center, Shandong University, Jinan, 250061, China \\ E-mails. ${ }^{1}$ fk861018@163.com (corresponding author); ${ }^{2}$ zjuzhangzhongmiao@163.com;
${ }^{3}$ liuxingwang@163.com; ${ }^{4}$ zhangqianqing@163.com; ${ }^{5}$ cungangl@163.com \\ Received 02 Apr. 2011; accepted 08 Jul. 2011
}

\begin{abstract}
A special double-row support structure used for braced excavation was modeled numerically using finite element method. The performance of the braced excavation depends on the interaction between the two walls of the support structure. Comprehensive parametric studies were carried out to investigate the influence factors on the performance. It was ascertained that the support structure behavior was largely influenced by overlapping length of two support walls, embedment ratio of inner support wall and spacing between two support walls. Appropriate parameters should be chosen to limit wall deflection and to maintain the stability of the support structure.
\end{abstract}

Keywords: double-row support structure, braced excavation, finite element analysis, parametric study.

Reference to this paper should be made as follows: Fang, K.; Zhang, Z.; Liu, X.; Zhang, Q.; Lin, C. 2013. Numerical analysis of the behavior of special double-row support structure, Journal of Civil Engineering and Management 19(2): 169-176.

\section{Introduction}

Braced excavation has been extensively used in urban areas, and the demands for support structure are increasing due to the space limitations and environmental concerns. When the planned excavation depth is increased temporarily after the completion of the support wall construction, the deflection and stability of the support wall may not satisfy the demands, so reinforcement measures should be taken to ensure the safety of the excavation. An inner support wall inside the original support wall was usually adopted (see Fig. 1) to satisfy the requirements of excavation stability and control of ground movements. Similar support structure is also used when a great elevation difference exist at the bottom of the excavation.

Unlike the traditional double-row piles which are connected at the top of the piles using connecting beams (Zheng et al. 2004), the two walls of the special double- row support structure are separated. Because the outer wall has been constructed, the design of the inner structure has a significant influence on the deflection and stability of the support structure. In view of the facts that the design of the double-row support structure is complicated due to the interaction between the outer and the inner walls, therefore, there is a need to model the excavation using a twodimensional finite element method to provide an insight to study and understand the behavior of the special structure and the interaction between the two walls.

Prediction of support wall deformation of a foundation excavation has been studied using plane strain finite element analysis by Palmer and his group (Palmer, Kenney 1972) and many other researchers (Potts, Fourie 1984; Powrie, Li 1991; Ou, Lai 1994; Bose, Som 1998; Yoo, Lee 2008). The results show that good correlation can be achieved between the finite element predictions and field observations. This paper describes the application of a finite element model for predicting the behavior of a special double-row support structure. A nonlinear, two-dimensional plane strain finite element analysis was developed to study the deformation performance of the double-row support structure and the results were compared with the field observations. Then parametric studies were carried out to investigate some influence factors on the deformation behavior. Based on the research findings, design recommendations were proposed for the use of the double-row support structures.

\section{Site descriptions and excavation sequence}

The excavation site is located at the intersection of Yanan Road and Pinghai Road in Hangzhou city. Fig. 2 shows the excavation site along with the surrounding conditions. Considering the complication 


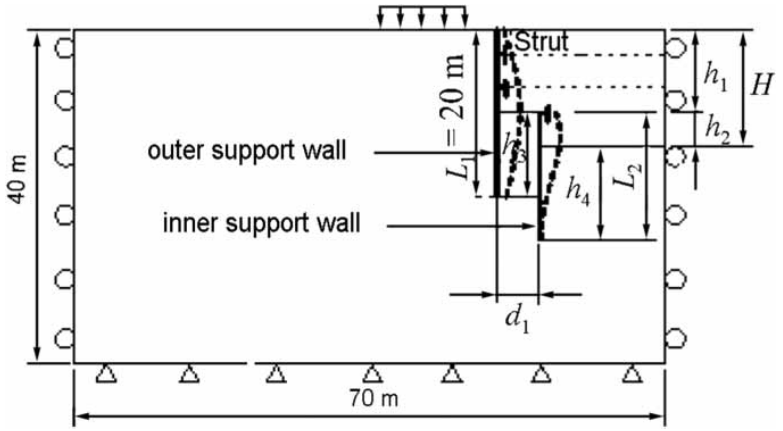

Fig. 1. Schematic of double-row support structure and model of FEM

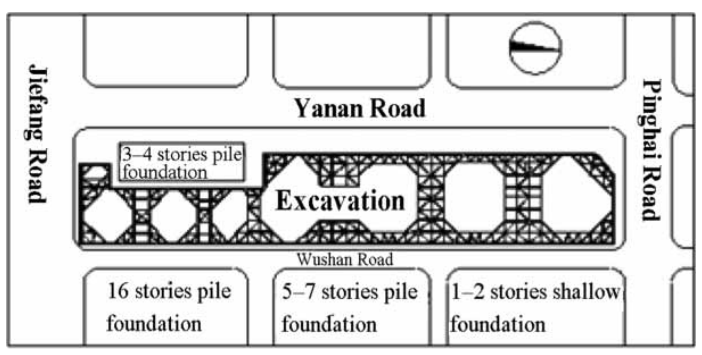

Fig. 2. Site location and surrounding conditions

of the adjacent environment, higher requirement has been put forward to the performance of the support structure. A reinforced concrete diaphragm wall extending down to $-20 \mathrm{~m}$ below the ground surface was designed as the permanent lateral earth pressure support for the original plan. However, after the completion of the diaphragm wall construction, the design excavation depth was changed from $10 \mathrm{~m}$ to $14 \mathrm{~m}$. Therefore, the original support structure should be reinforced to satisfy the requirements of deformation and stability. Thus an inner support structure was installed to reduce the deflection of the toe and increase the stability of the excavation.

The profile of subsurface stratigraphy interpreted from a series of borings conducted at the site is shown in Fig. 3. The fill layer comprises a heterogeneous mixture of clay, sand and construction debris with thickness ranging from 0.9 to $6 \mathrm{~m}$. Underlying the fill is a layer of slightly dense silt whose thickness varies from 5 to $10 \mathrm{~m}$. Beneath the silt is the layer of clay. It consists of a layer of lightly overconsolidated clay, which has an overconsolidation ratio ranging from 1 to 2 , and the overlying soft silt clay.

The construction sequence of the excavation is shown in Fig. 3. Two stages were included in the excavation process: (1) Stage 1: I. The diaphragm wall was installed prior to excavation. And the soil was initially excavated to a depth, $3 \mathrm{~m}$, without lateral support; II. The first level of support was installed and excavation proceeded to a depth $7 \mathrm{~m}$ and then a second level of support was installed; (2) Stage 2: I. After the excavation reached a depth $10 \mathrm{~m}$, the inner

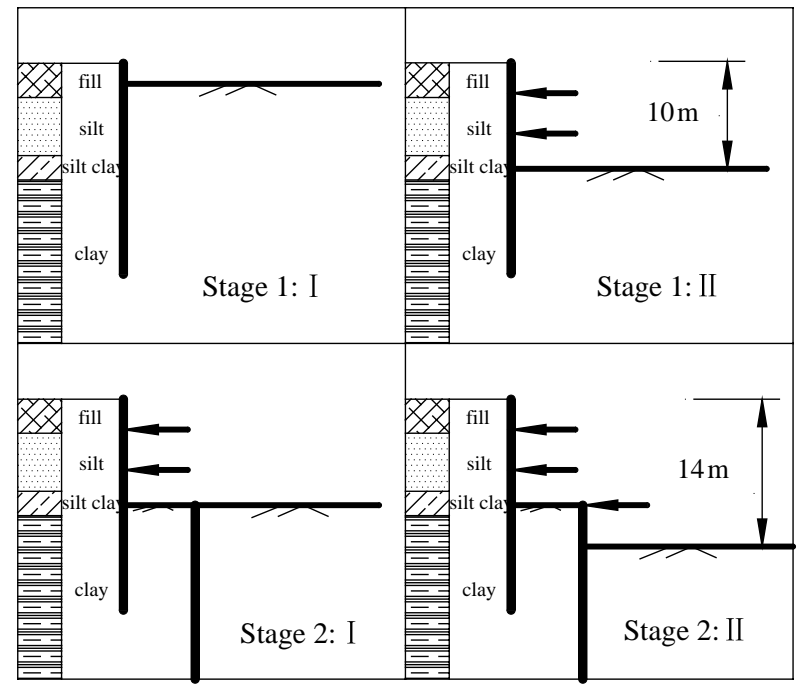

Fig. 3. Subsurface conditions and excavation sequence

wall was installed and was propped at the excavation surface; II. The excavation proceeded to a depth $14 \mathrm{~m}$ in the area supported by the inner wall.

\section{Finite element analyses}

A nonlinear, two-dimensional plane strain finite element analysis was developed to study the deformation performance of support structure using the Plaxis software. Assuming the excavation was symmetric, only a half of the excavation was needed to be modeled and considered. Fig. 1 shows the analysis model, in which the vertical boundaries were supported with rollers and the base were supported with hinges. Analysis was performed following the actual excavation procedure. It is assumed that support structure construction had no significant effect on the in situ stresses of soil. The ground water table was considered at the level of excavation surface inside the excavation pit. And seepage was considered in simulation.

\subsection{Soil model}

Selection of an adequate soil model that is capable of adequately describing the stress-strain-strength characteristic of the soils is important for the problem of excavation. Some studies have concluded that the capability of a soil model to describe the property of the soils at small-strain levels plays a crucial role in the finite element analysis (Kung et al. 2009; Tang, Kung 2010). In this analysis, the soil was material assumed to behave as an elastic-plastic described by Hardening-Soil model with small-strain stiffness.

The hardening-soil model is an advanced model which is formulated in the framework of hardening multi-surface plasticity. In this model the total strains are calculated using a stress-dependent stiffness, different for both virgin loading and reloading. The plastic strains are calculated by introducing a multisurface yield criterion. Hardening is assumed to be 


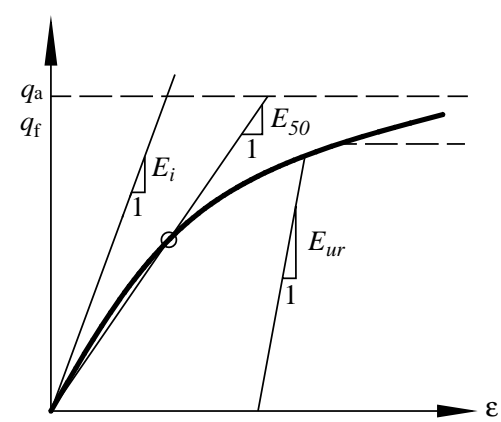

Fig. 4. Hyperbolic stress-strain relation in primary loading for a standard drained triaxial test

isotropic depending on both the plastic shear and volumetric strain. Shear hardening is used to model irreversible strains due to primary deviatoric loading. Compression hardening is used to model irreversible plastic strains due to primary compression in oedometer loading and isotropic loading.

The formulation of the Hardening-Soil model is the hyperbolic relationship between the vertical strain $\varepsilon_{1}$, and the deviatoric stress, $q$, in primary triaxial loading, as shown in Fig. 4.

The ultimate deviatoric stress, $q_{\mathrm{f}}$, is derived from the Mohr-Coulomb failure criterion as Eq. (1), which involved the strength parameters cohesion $c$ and internal friction angle $\varphi$ :

$$
q_{\mathrm{f}}=\frac{2 \sin \varphi}{1-\sin \varphi}\left(c \cot \varphi-\sigma_{3}^{\prime}\right) .
$$

The parameter $E_{50}$ is the confining stress dependent stiffness modulus for primary loading. $E_{50}$ is used instead of the initial modulus $E_{i}$ for small strain and defined as:

$$
E_{50}=E_{50}^{\mathrm{ref}}\left(\frac{c \cot \varphi-\sigma_{3}^{\prime}}{c \cot \varphi+p^{r e f}}\right)^{m}
$$

where $E_{50}^{\text {ref }}$ is a reference stiffness modulus corresponding to the reference stress $p^{r e f}$ and is derived from a triaxial stress-strain curve for a mobilization of $50 \%$ of the maximum shear strength.

The actual stiffness depended on the minor principal stress, $\sigma_{3}^{\prime}$, which is the effective confining pressure in a triaxial test. The amount of stress dependency is given by the power $m$.
The parameter $E_{\mathrm{ur}}$ can be defined as:

$$
E_{\mathrm{ur}}=E_{\mathrm{ur}}^{\mathrm{ref}}\left(\frac{c \cot \varphi-\sigma_{3}^{\prime}}{c \cot \varphi+p^{r e f}}\right)^{m},
$$

where $E_{\mathrm{ur}}^{\mathrm{ref}}$ is the reference Young's modulus for unloading and reloading, corresponding to the reference pressure $p^{r e f}$.

Atkinson and Sallfors (1991) proposed that shear modulus varied with shear strain where higher degrees emerged at small strains. For the problem of excavation, the low-level strains that relevant level for practical problem would lead to higher stiffness than that from conventional laboratory. Consequently, the stiffness of soil in an excavation problem would be higher than the value normally used. The HardeningSoil model with small-strain stiffness accounts for the increased stiffness of soils at small strains. This behavior is described using an additional strainhistory and two additional material parameters, i.e. $G_{0}$ and $\gamma_{0.7} . G_{0}$ is the small-strain shear modulus and $\gamma_{0.7}$ is the strain level at which the shear modulus decreases $70 \%$ of the small-strain shear modulus.

$G_{0}^{\text {ref }}$ defines the shear modulus at very small strains e.g. $\varepsilon<10^{-6}$ at a reference minor principal stress of $\sigma_{3}^{\prime}=p^{r e f}$. In this model, the stress dependency of the shear modulus $G_{0}$ is taken into account with the power law:

$$
G_{0}=G_{0}^{\mathrm{ref}}\left(\frac{c \cos \varphi-\sigma_{1}^{\prime} \sin \varphi}{c \cos \varphi+p^{\mathrm{ref}} \sin \varphi}\right)^{m} .
$$

\subsection{Parameters of model}

Table 1 shows the parameters of model for each layer used in the finite element analysis. According to a series of numerical experiments conducted by Calvello and Finno (2004), the failure parameter $\varphi$ and the stiffness parameters $E_{50}^{\text {ref }}$ were the main parameters that affect the observations and should be optimized by inverse analysis. In this study, the strength parameters were directly obtained from laboratory tests and only the stiffness parameter $E_{50}^{\text {ref }}$ were obtained from back analysis. Other stiffness parameters were determined by the derived $E_{50}^{\text {ref }}$ and experience. The

\begin{tabular}{|c|c|c|c|c|c|c|c|c|c|c|c|c|}
\hline Parameter & $\gamma_{\text {unsat }} / \gamma_{\text {sat }}$ & $c$ & $\varphi$ & $\psi$ & $k_{x} / k_{y}$ & $E_{50}^{\mathrm{ref}}$ & $E_{\mathrm{ur}}^{\mathrm{ref}}$ & $G_{0}^{r e f}$ & $p^{r e f}$ & $\gamma_{0.7}$ & $m$ & $R_{\text {inter }}$ \\
\hline Unit & $\mathrm{kN} / \mathrm{m}^{3}$ & $\mathrm{kN} / \mathrm{m}^{2}$ & degree & degree & $\mathrm{m} /$ day & $\mathrm{kN} / \mathrm{m}^{2}$ & $\mathrm{kN} / \mathrm{m}^{2}$ & $\mathrm{kN} / \mathrm{m}^{2}$ & $\mathrm{kN} / \mathrm{m}^{2}$ & & & \\
\hline Fill & $17.5 / 20$ & 12 & 15 & 0 & 0.026 & $2 \mathrm{e} 4$ & $6 \mathrm{e} 4$ & $6 e 4$ & 100 & $2 e-4$ & 0.8 & 0.9 \\
\hline Silt & $18.5 / 20$ & 21 & 16 & 0 & 0.015 & $3.2 \mathrm{e} 4$ & $9.6 \mathrm{e} 4$ & $9.6 \mathrm{e} 4$ & 100 & $2 e-4$ & 0.8 & 1 \\
\hline Silt clay & $18 / 20$ & 10 & 8 & 0 & $4 e-4$ & $1.6 \mathrm{e} 4$ & $4.8 \mathrm{e} 4$ & $4.8 \mathrm{e} 4$ & 100 & $2 e-4$ & 0.65 & 1 \\
\hline Clay & $18 / 20$ & 10 & 30 & 0 & $1 e-4$ & $2.8 \mathrm{e} 4$ & $8.4 \mathrm{e} 4$ & $9 \mathrm{e} 4$ & 100 & $2 e-4$ & 1 & 1 \\
\hline
\end{tabular}
properties of support wall and bracing struts are shown in Tables 2 and 3, respectively.

Table 1. Soil properties used for finite element analysis 
Table 2. Support wall properties used for finite element analysis

\begin{tabular}{lcccc}
\hline Parameter & Axial stiffness & Flexural rigidity & Equivalent thickness & Poisson's ratio \\
\hline Value & $1.2 \mathrm{e} 7 \mathrm{kN} / \mathrm{m}$ & $1.0 \mathrm{e} 6 \mathrm{kNm}^{2} / \mathrm{m}$ & $1 \mathrm{~m}$ & 0.15 \\
\hline
\end{tabular}

Table 3. Bracing struts properties used for finite element analysis

\begin{tabular}{lcc}
\hline Parameter & Axial stiffness & Horizontal spacing \\
\hline Value & $2 \mathrm{e} 5 \mathrm{kN}$ & $2 \mathrm{~m}$ \\
\hline
\end{tabular}

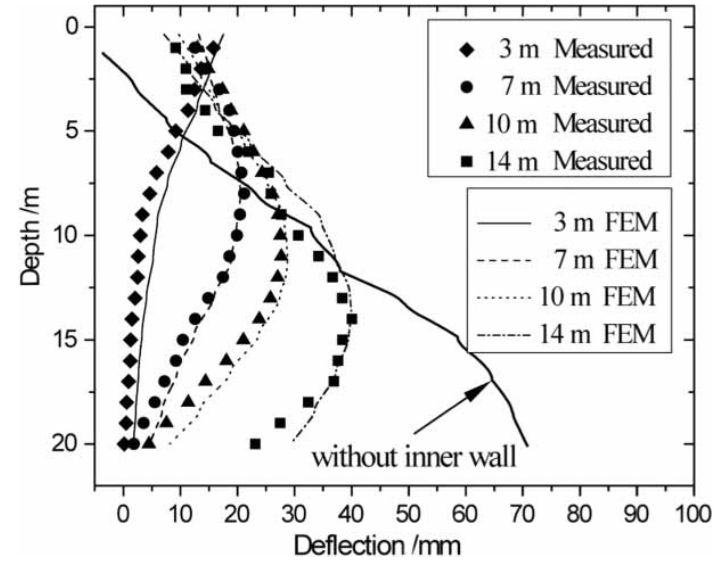

Fig. 5. Comparison of measured and calculated outer wall deflections for different excavation depths

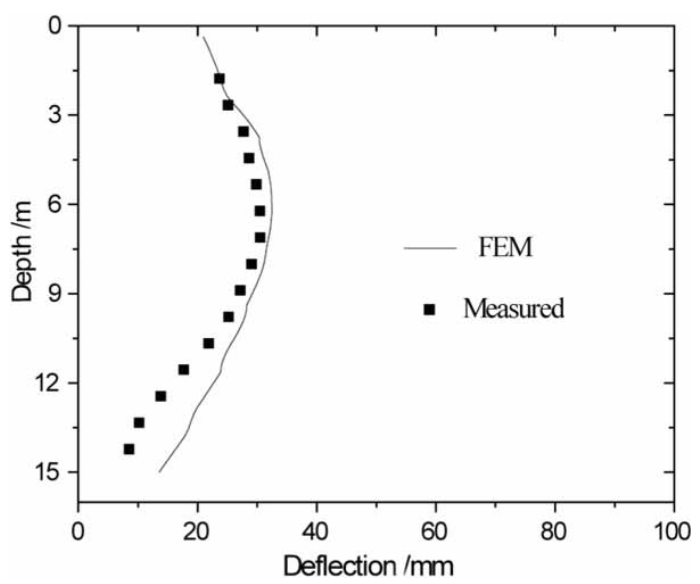

Fig. 6. Comparison of measured and calculated inner wall deflections

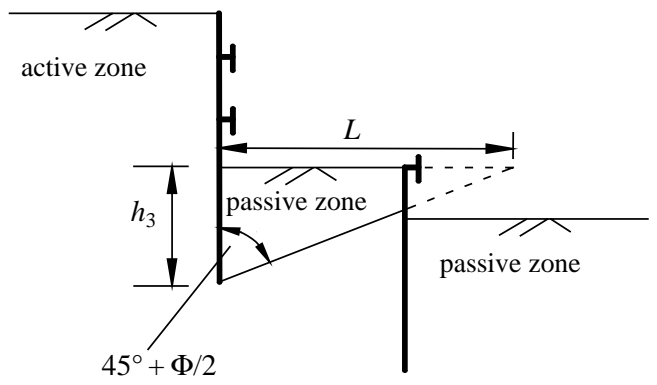

Fig. 7. Interaction between the walls

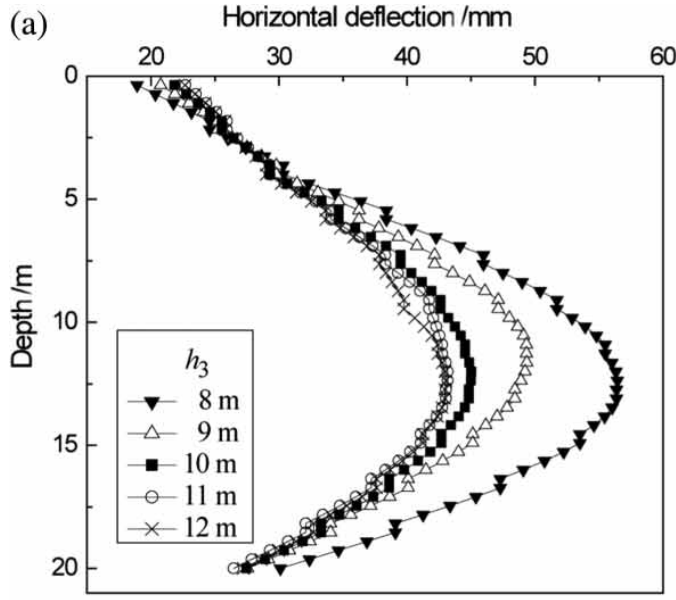

(b)

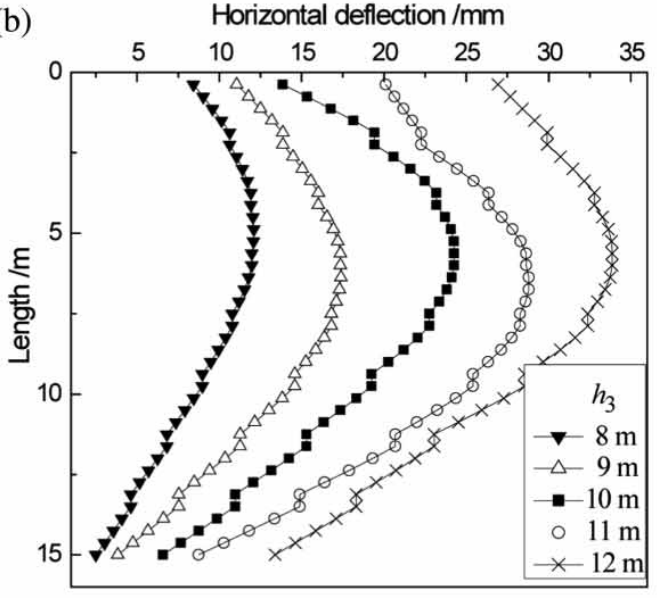

(c)

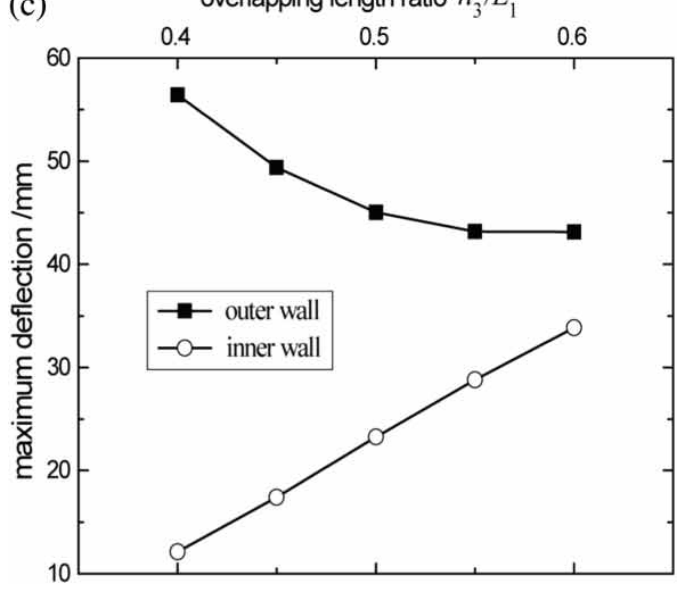

Fig. 8. Support wall horizontal deflection at final excavation level for different overlapping lengths: (a) outer wall; (b) inner wall; (c) maximum deflection 


\subsection{Results of numerical simulation}

Figs 5 and 6 show the comparison of the plane strain finite element analysis results and the field measurements for inclinometers. The results show close agreement between the finite element analysis results and the field observations. The maximum deflection of the outer wall is $40 \mathrm{~mm}$, which is $0.3 \% H$ (where $H$ is the excavation depth). The maximum deflection of the inner wall is $30 \mathrm{~mm}$, which is $0.2 \% \mathrm{H}$. While the maximum horizontal deflection reached to $70 \mathrm{~mm}$ for the situation without the existence of inner wall. Large deformation is observed at the bottom of the support structure due to the low embedment depth. This will reduce substantially the base stability of the excavation. It indicates that the existence of inner support wall decreases the deflection of outer wall and increases the stability of the excavation.

\section{Parametric studies}

The behavior of the special support structure is determined by the interaction between the two walls.
As is shown in Fig. 7, the earth pressure against the inner wall is significantly affected by the passive earth pressure in passive zone of the outer wall. The angle between the wall and the sliding surface is $45^{\circ}+\varphi / 2$ following Rankin theory. Then the influence distance of the two walls can be written as:

$$
L=h_{3} \tan \left(45^{\circ}+\varphi / 2\right)
$$

If the spacing between the two walls $d_{1}$ is greater than the influence distance $L$, it can be assumed that the interaction is negligible.

Apart from the spacing between the two walls, other geometries of the support structure, such as overlapping length of the two support walls, embedment ratio of inner support structure, also have significant role to play on the performances as well optimization requirement for excavation stability. Hence, parametric studies were carried out to investigate these influence factors. In these parametric studies, the soil was considered to be homogenous and properties used for finite element analysis can be found in Table 1 (Clay). The length of the outer wall

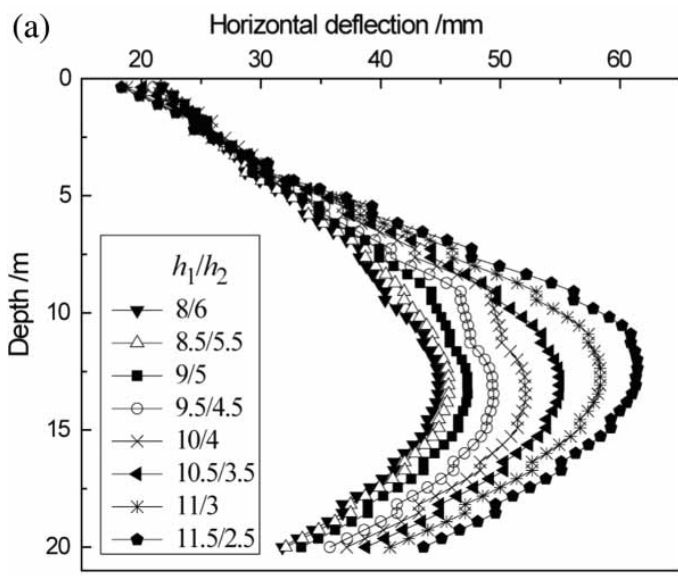

(b)
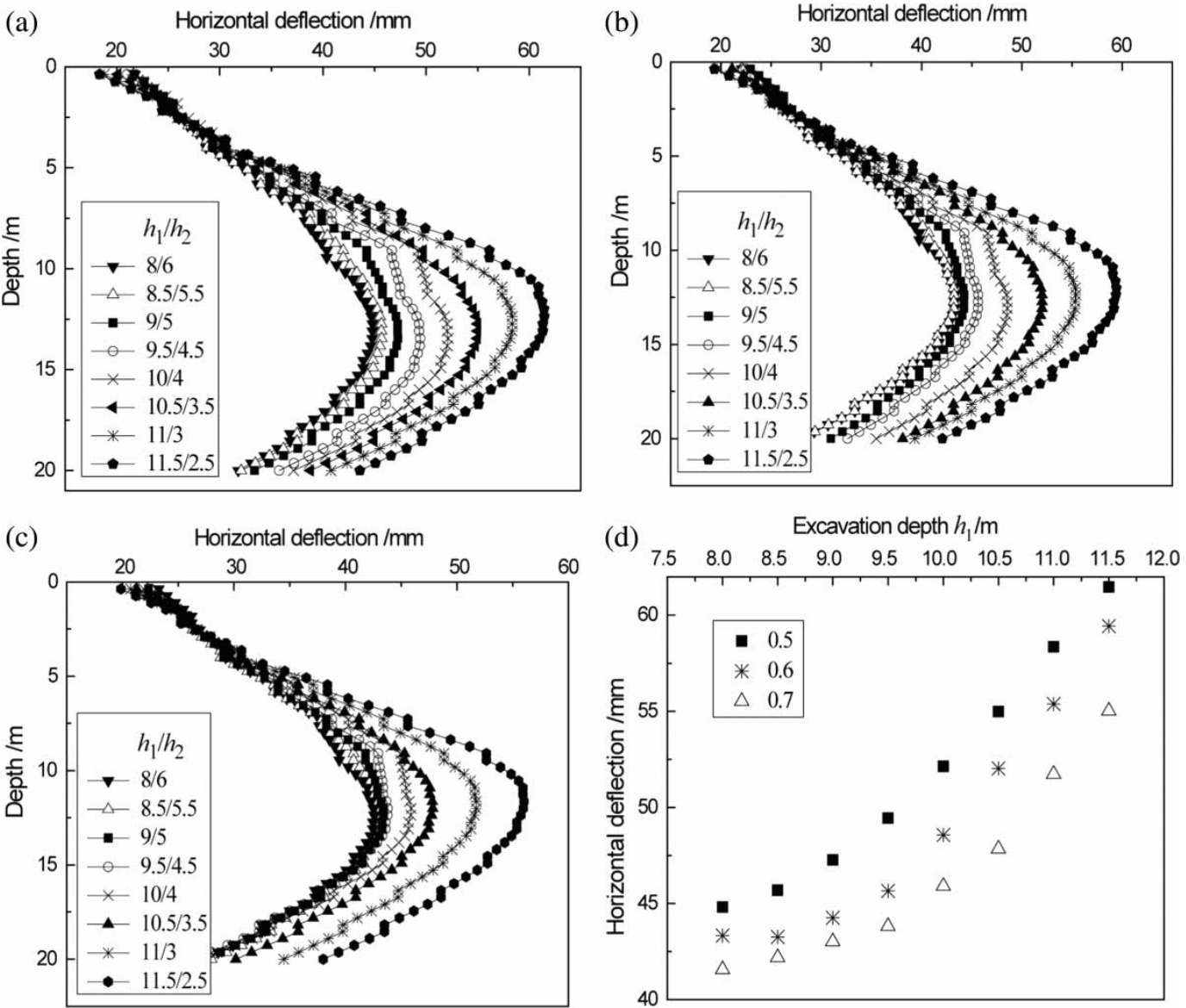

Fig. 9. Outer wall horizontal deflection at final excavation level for different embedment ratio of the inner support structure: (a) ratio of 0.5 ; (b) ratio of 0.6 ; (c) ratio of 0.7 (d) maximum deflection of outer wall for different embedding ratios of the inner support structure 
and the total depth of excavation were kept to be constant.

In this section, the influence of overlapping length ( $h_{3}$ in Fig. 1) on the support structures was studied. Analyses were done with the same excavation scheme as shown in Fig. 1 with $h_{3}$ of $8 \mathrm{~m}, 9 \mathrm{~m}, 10 \mathrm{~m}$, $11 \mathrm{~m}, 12 \mathrm{~m}$ and the total length of the inner wall remains constant, i.e. $15 \mathrm{~m}$. The results of analyses carried out for the final stage of excavation are presented in terms of wall deflection in Fig. 8.

It can be found from the results that as the overlapping length of the two wall increases, the magnitude of the outer wall deflection get reduced which are opposite to the behavior of inner wall. It has also been found from a plot of maximum deflection of the two walls, for the final cut level, against overlapping length ratio $h_{3} / L_{1}$ that the maximum deflection of inner wall increases linearly with the increase in overlapping length, while it reduced exponentially for outer wall. Therefore, the increase of overlapping length is effective to reduce the deflection of the outer wall, thus reducing ground movement outside the excavation; but it also lead to more deflection deformation of the inner wall, which decreases the stability of the inner wall.

A comprehensive study on the influence of different excavation depths for two stages $h_{1}$ and $h_{2}$ on the performance of the braced excavation was carried out. Excavation with constant total excavation depth $(14 \mathrm{~m})$ and various two stages excavation depth $h_{1}(8$ to $11.5 \mathrm{~m})$ and $h_{2}(6$ to $2.5 \mathrm{~m})$ were analyzed. Analyses were further done by varying the embedment depth of the inner support wall $\left(h_{4}\right.$ in Fig. 1) to investigate its effect on wall deflection. For instance, if the first stage excavation depth $h_{1}$ was $9 \mathrm{~m}$, then the second stage excavation depth $h_{2}$ was $5 \mathrm{~m}$ and the embedment depth of inner wall with an embedment ratio (which is defined as $h_{4} / L_{2}$ ) of 0.5 was $5 \mathrm{~m}$. The results of the analyses for the final cut level are summarized in Figs. 9 and 10, respectively. The results from Fig. 9 show that horizontal deflection of the outer wall increases with the increase in first stage excavation depth $h_{1}$, and the maximum deflection of the wall increases exponentially with $h_{1}$. It also can be investigated from Fig. 9 that the outer wall deflection decreases with increasing embedment ratio of the
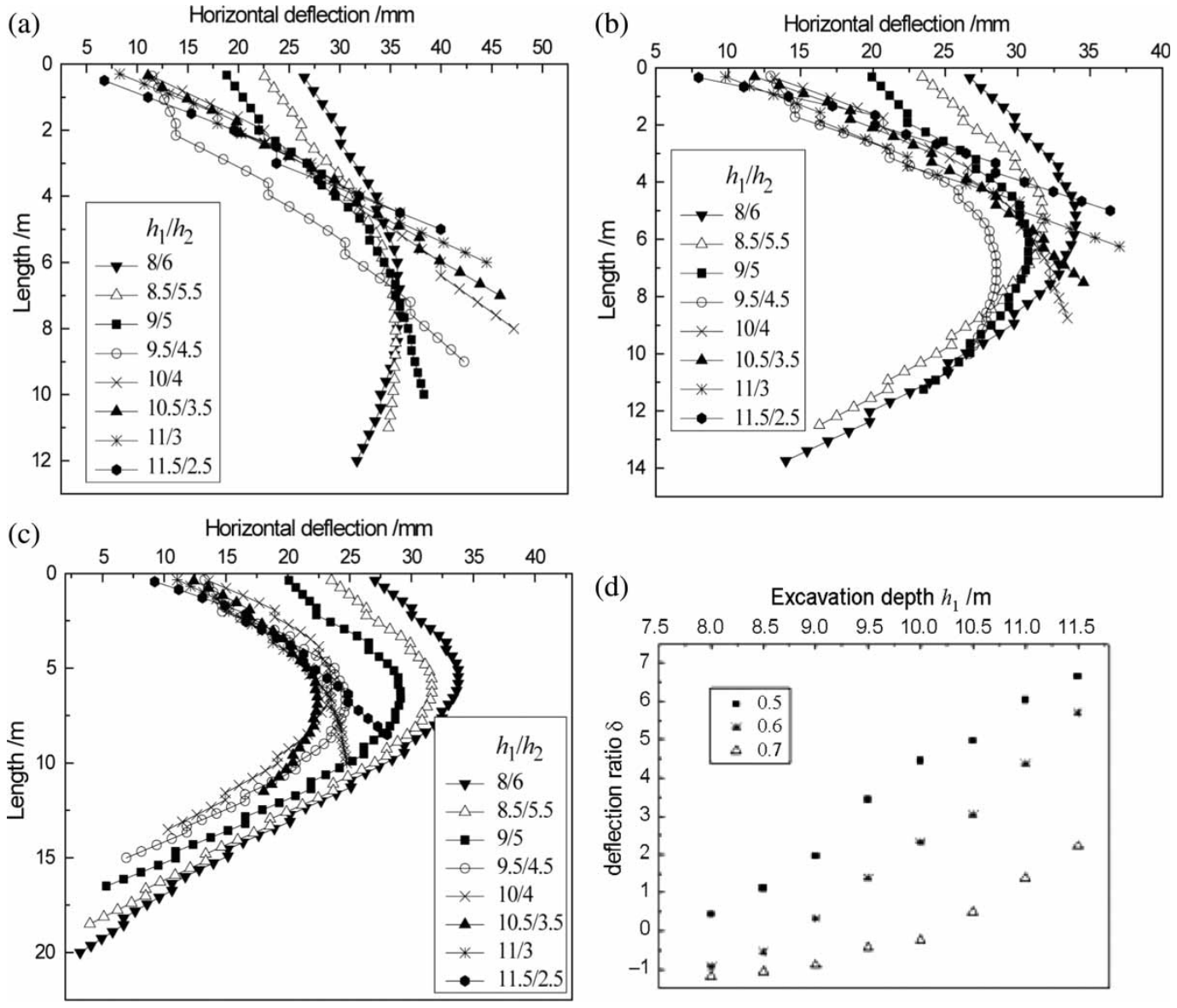

Fig. 10. Inner wall horizontal deflection at final excavation level for different embedment ratios of the inner support structure: (a) ratio of 0.5 ; (b) ratio of 0.6 ; (c) ratio of 0.7 ; (d) deflection ratio of inner wall for different embedding ratios of the inner support structure 
inner wall while no significant change is evident for the upper $5 \mathrm{~m}$ of the outer wall.

Fig. 10 shows the inner wall horizontal deflection at final excavation level for different embedment ratios of the inner support wall. The deflection ratio $\delta$ in Fig. 10 was defined as the deflection difference between the toe of the wall and the top of the wall normalized by the length of the inner wall, which can be written as:

$$
\delta=\frac{\Delta_{\text {toe }}-\Delta_{\text {top }}}{L_{2}},
$$

where: $\Delta_{\text {toe }}$ is the deflection of wall toe; $\Delta_{\text {top }}$ is the deflection of wall top; $L_{2}$ is the length of inner wall.

Fig. 10 presents that the more the wall extends below the bottom of cut, the more is the fixity of the wall at the base. The deflection ratio, $\delta$, increases with increasing first stage excavation depth $h_{1}$, and decreases with increasing embedment depth. It is also found that the deflection of inner wall toe is much larger than the top when the second stage excavation depth $h_{2}$ is large and the embedment ratio is small. Therefore, to ensure stability, inner wall should be
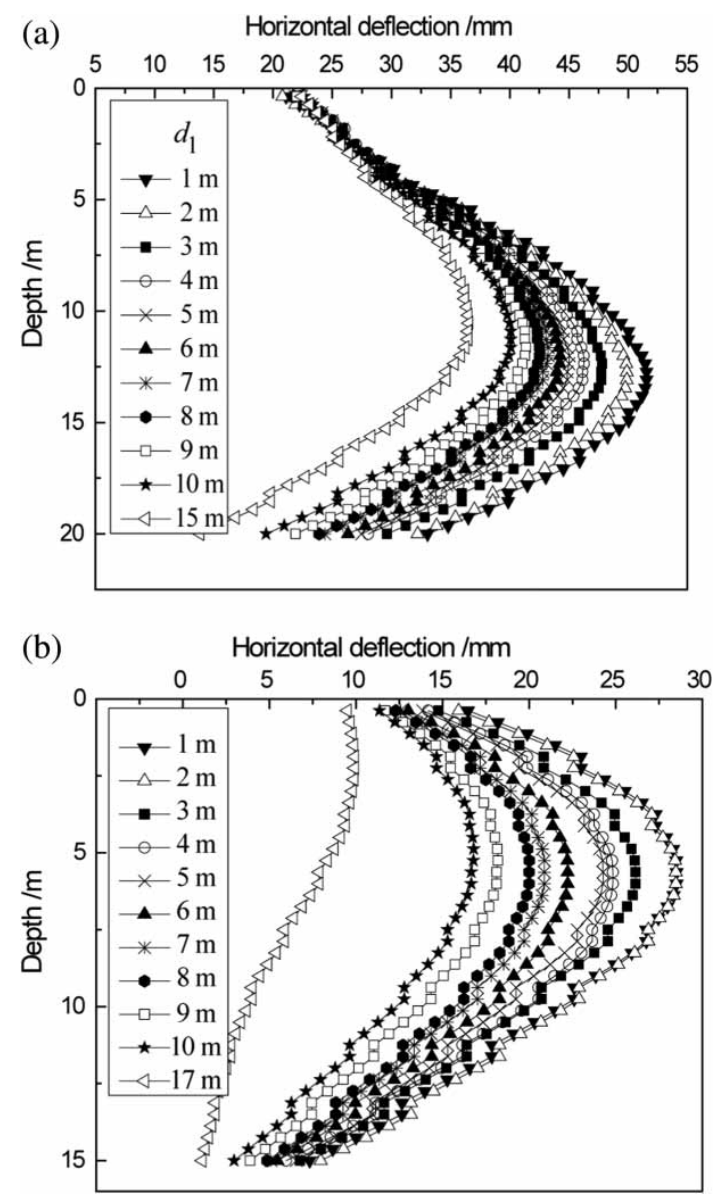

Fig. 11. Wall horizontal deflection at final excavation level for different distances between the two walls: (a) outer wall and (b) inner wall

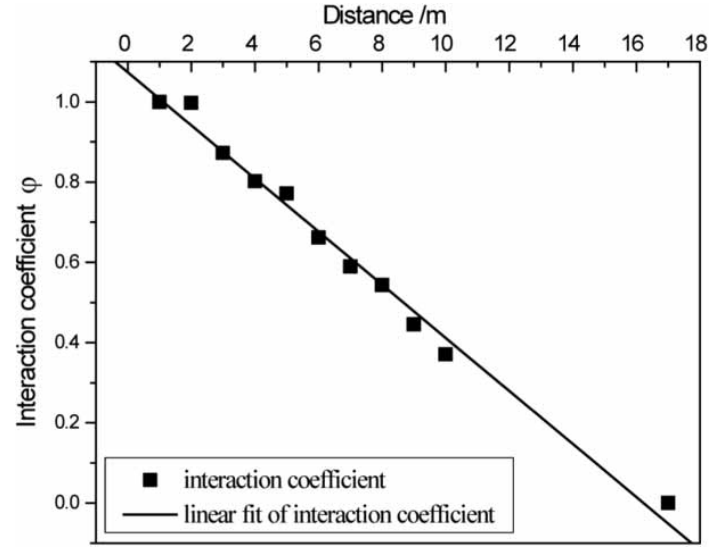

Fig. 12. Linear fit of interaction coefficient between the outer wall and the inner wall

embedded to adequate depth below the final excavation level.

Analyses were further done by varying spacing between the two walls, $d_{1}$, to investigate its effect on the wall deflection. The spacing, $d_{1}$, was varied from $1 \mathrm{~m}$ to $17 \mathrm{~m}$. The results of the analyses for the final cut level are summarized in Fig. 11. It is observed from Fig. 11 that both of the two walls deflection decrease with the increasing spacing between them. It illustrates that increasing spacing reduces the interaction between the two walls, suggesting that choosing an appropriate spacing between the two walls for practical application can satisfy the requirement of deformation and stability.

The earth pressure in passive zone of the outer wall acted as the earth pressure in active zone for the inner wall. So an interaction coefficient $\varphi$ was introduced to reflect the interaction between the two walls. It is assumed that the interaction coefficient equals to 1 and 0 when the distances between the two walls are $1 \mathrm{~m}$ and $17 \mathrm{~m}$, respectively. For a distance of $i$, the interaction coefficient can be defined as:

$$
\varphi=\frac{\Delta_{\mathrm{i}}-\Delta_{17}}{\Delta_{1}-\Delta_{17}}
$$

where $\Delta_{i}$ is the maximum deflection of the inner wall for the spacing of $i$ which can be obtained from Fig. $11 ; \Delta_{1}$ and $\Delta_{17}$ are the maximum deflection of the inner wall for the distance of $1 \mathrm{~m}$ and $17 \mathrm{~m}$, respectively.

Best fit plot of interaction coefficient is shown in Fig. 12. It is observed that the interaction coefficient decreases linearly with increasing spacing between the two walls.

\section{Conclusions}

A special double-row support structure was modeled numerically using finite element method. And comprehensive parametric studies were carried out to investigate the influence factors on the performance. 
The following conclusions are drawn based on this study:

1. The maximum deflection of the outer wall is $0.3 \% \mathrm{H}$, while the maximum deflection of the inner wall is $0.2 \% H$. The existence of inner support wall decreases the deflection of outer wall and increase the stability of the excavation.

2. The maximum deflection of inner wall increases linearly with the increase in overlapping length, while it reduced exponentially for outer wall. It's effective to reduce the deflection of the outer wall but unfavorable to maintain the stability of the inner wall for a large overlapping length.

3. With the increasing embedment ratio of the inner wall, the deflections of both two walls decrease. And different excavation depths for two stages influence the performance of the support structure greatly. To maintain the stability of the inner wall, excavation depth for the first stage and the embedment ratio should not be too small.

4. Interaction coefficient was introduced to investigate the interaction between the two walls. The interaction coefficient decreases linearly with increasing spacing between the two walls.

\section{References}

Atkinson, J. H.; Sallfors, G. 1991. Experimental determination of soil properties, in Proc. of the 10th European Conference on Soil Mechanics, 1991, Florence, Italy, 915-956.

Bose, S. K.; Som, N. N. 1998. Parametric study of a braced cut by finite element method, Computers and Geotechnics 22(2): 91-107. http://dx.doi.org/10.1016/S0266-352X(97)00033-5
Calvello, M.; Finno, R. J. 2004. Selecting parameters to optimize in model calibration by inverse analysis, Computers and Geotechnics 31(5): 410-424. http://dx.doi.org/10.1016/j.compgeo.2004.03.004

Kung, G. T.-C.; Ou, C.-Y.; Juang, C. H. 2009. Modeling small-strain behavior of Taipei clays for finite element analysis of braced excavations, Computers and Geotechnics 36(1-2): 304-319. http://dx.doi.org/10.1016/j.compgeo.2008.01.007

Ou, C.-Y.; Lai, C.-H. 1994. Finite-element analysis of deep excavation in layered sandy and clayey soil deposits, Canadian Geotechnical Journal 31(2): 204-214. http://dx.doi.org/10.1139/t94-026

Palmer, J. H. La Verne.; Kenney, T. C. 1972. Analytical study of a braced excavation in weak clay, Canadian Geotechnical Journal 9(2):145-164. http://dx.doi.org/10.1139/t72-016

Potts, D. M.; Fourie, A. B. 1984. The behaviour of a propped retaining wall: results of a numerical experiment, Geotechnique 34(3): 384-404. http://dx.doi.org/10.1680/geot.1984.34.3.383

Powrie, W.; Li, E. S. F. 1991. Finite element analyses of an in situ wall propped at formation level, Geotechnique 41(4): 499-514. http://dx.doi.org/10.1680/geot.1991.41.4.499

Tang, Y.-G.; Kung, G. T.-C. 2010. Investigating the effect of soil models on deformations caused by braced excavation through an inverse-analysis technique, Computers and Geotechnics 37(6): 769-780. http://dx.doi.org/10.1016/j.compgeo.2010.06.003

Yoo, C.; Lee, D. 2008. Deep excavation-induced ground surface movement characteristics - a numerical investigation, Computers and Geotechnics 35(2): 231-252. http://dx.doi.org/10.1016/j.compgeo.2007.05.002

Zheng, G.; Li, X.; Liu, C. 2004. Analysis of double-row piles in consideration of the pile-soil interaction, Journal of Building Structures 25(1): 99-106.

Kai FANG. PhD student in Institute of Geotechnical Engineering, Zhejiang University. Research interests: soil mechanics, pile foundation, excavation engineering.

Zhongmiao ZHANG. Professor, Doctoral supervisor in Institute of Geotechnical Engineering, Zhejiang University. Research interests: pile foundation, soil mechanics.

Xingwang LIU. Professor in Zhejiang Province Institute of Architectural Design and Research. Research interests: excavation engineering, foundation engineering.

Qianqing ZHANG. Lecturer of Geotechnical and Structural Engineering Research Center, Shandong University. Research interests: pile foundation, rock mechanics.

Cungang LIN. PhD student in Institute of Geotechnical Engineering, Zhejiang University. Research interests: tunnel engineering. 